\title{
Sepsis Heterogeneity and Progression: Appraisal of Scoring System [Letter]
}

\author{
Honglian Huang ${ }^{1} *$, Renjie Wei ${ }^{1} *$, Haihang Qin $^{2}$ \\ 'Hechi People's Hospital, Hechi City, Guangxi Zhuang Autonomous Region, People's Republic of China; ${ }^{2}$ Hechi Third People's Hospital, Hechi City, \\ Guangxi Zhuang Autonomous Region, People's Republic of China \\ *These authors contributed equally to this work \\ Correspondence: Haihang Qin, Hechi Third People's Hospital, No. 229 Nanxin East Road, Jinchengjiang District, Hechi City, Guangxi Zhuang
} Autonomous Region, 547000, People's Republic of China, Tel/Fax +86 778-2302792, Email qinhaihang@I63.com

\section{Dear editor}

We read with great interest of this study ${ }^{1}$ titled "Establishment and Effectiveness Evaluation of a Scoring System-RAAS (RDW, AGE, APACHE II, SOFA) for Sepsis by a Retrospective Analysis”. This study established a RAAS score system as a novel and reliable indicator to predict the short-term and medium-term mortality of patients with sepsis.

Sepsis is one of the important causes of death in critically ill patients in the intensive care unit (ICU) and emergency departments. Existing studies ${ }^{2}$ have shown that the fatality rate of patients with severe sepsis and septic shock is as high as $20 \% \sim 54 \%$.

Herein, we have several thoughts we wanted to discuss regarding this study.

1. The heterogeneity of sepsis

The RAAS scoring might be improved in prediction if sepsis patients were stratified. The morbidity of sepsis is heterogeneous ${ }^{3}$ and systemic. In the Molecular Diagnosis and Risk Stratification of Sepsis (MARS) prospective cohort, the patients with sepsis were divided based on source of infection. Stratification of sepsis source of infection is part of the regulation of host immune response. This is the reason the heterogeneity should be considered when predicting the prognosis.

2. The rationale of parameter selection

(a) The pathogenesis of sepsis and selection of RDW

Sepsis mainly invades the vascular endothelial system, and the microvascular endothelium is the main target of sepsis, which is characterized by vascular microcirculation dysfunction. Red cell distribution width (RDW) describes the variation in the size of red blood cells. RDW can be a valuable test estimating mortality or cancer risks. ${ }^{4}$ We agree with the authors in choosing RDW as a parameter in prediction.

(b) The scoring system constituent's comparison

The APACHE II score is composed of acute physiological score, age score and chronic health score. Since APACHE II already recruited age as a parameter, the logic of using age as another independent factor besides APACHE II needs to be considered.

The SOFA score uses six criteria to reflect the function of organ systems (respiratory, blood, liver, cardiovascular, nervous, and renal systems) and assigns each item a score of $0-4$. The blood parameters of SOFA overlap with the APS score inside APACHE II. 
(c) The relationship between dynamic changes of the score monitoring and disease progression

Considering the parameter age included in this scoring system is constant, the progression of sepsis might be better adjusted to overcome this issue.

3. Nonsuperiority comparison of the RAAS scoring of current best practice

In the latest study ${ }^{5}$ comparing several scoring systems, the National Early Warning Score (NEWS) was discovered to be a idealistic one in clinical practice with better sensitivity and specificity than SOFA alone.

We are interested in the comparison of RAAS and NEWS, partly due to the reason NEWS has been already applied in clinical practice in the UK.

After all, we congratulate the authors for successfully establishing the RAAS system for the assisted prediction model. We look forward to their future applications and trials.

\section{Disclosure}

The authors report no conflicts of interest in this communication.

\section{References}

1. Yingying Huang SJ, Wenjie L, Leng Y, Leng Y, Gao C, Gao C. Establishment and effectiveness evaluation of a scoring system-RAAS (RDW, AGE, APACHE II, SOFA) for sepsis by a retrospective analysis. J Inflamm Res. 2022;15:465-474. doi:10.2147/JIR.S348490

2. Paoli CJ, Reynolds MA, Sinha M, Gitlin M, Crouser E. Epidemiology and costs of sepsis in the United States-an analysis based on timing of diagnosis and severity level. Crit Care Med. 2018;46(12):1889-1897. doi:10.1097/CCM.0000000000003342

3. Peters-Sengers H, Butler JM, Uhel F, et al. Source-specific host response and outcomes in critically ill patients with sepsis: a prospective cohort study. Intensive Care Med. 2022;48(1):92-102. doi:10.1007/s00134-021-06574-0

4. Arbel Y, Weitzman D, Raz R, et al. Red blood cell distribution width and the risk of cardiovascular morbidity and all-cause mortality. A populationbased study. Thromb Haemost. 2014;111(2):300-307. doi:10.1160/TH13-07-0567

5. Churpek MM, Snyder A, Han X, et al. Quick sepsis-related organ failure assessment, systemic inflammatory response syndrome, and early warning scores for detecting clinical deterioration in infected patients outside the intensive care unit. Am J Respir Crit Care Med. 2017;195(7):906-911. doi:10.1164/rccm.201604-0854OC

Dove Medical Press encourages responsible, free and frank academic debate. The content of the Journal of Inflammation Research 'letters to the editor' section does not necessarily represent the views of Dove Medical Press, its officers, agents, employees, related entities or the Journal of Inflammation Research editors. While all reasonable steps have been taken to confirm the content of each letter, Dove Medical Press accepts no liability in respect of the content of any letter, nor is it responsible for the content and accuracy of any letter to the editor.

Journal of Inflammation Research

\section{Publish your work in this journal}

The Journal of Inflammation Research is an international, peer-reviewed open-access journal that welcomes laboratory and clinical findings on the molecular basis, cell biology and pharmacology of inflammation including original research, reviews, symposium reports, hypothesis formation and commentaries on: acute/chronic inflammation; mediators of inflammation; cellular processes; molecular mechanisms; pharmacology and novel anti-inflammatory drugs; clinical conditions involving inflammation. The manuscript management system is completely online and includes a very quick and fair peer-review system. Visit http://www.dovepress.com/testimonials.php to read real quotes from published authors. 